\title{
Influence of body condition on the population dynamics of Atlantic salmon with consideration of the potential impact of sea lice
}

\author{
R Susdorf $^{1,2}$ (D) | N K G Salama ${ }^{2}$ (D) | D Lusseau ${ }^{1}$
}

${ }^{1}$ Institute of Biological and Environmental Sciences, University of Aberdeen, Aberdeen, UK

${ }^{2}$ Marine Laboratory, Marine Scotland Science, Aberdeen, UK

\section{Correspondence}

R Susdorf, Institute of Biological and Environmental Sciences, University of Aberdeen, Aberdeen, UK.

Email: r.susdorf@abdn.ac.uk

\begin{abstract}
Atlantic salmon Salmo salar is an iconic species of high conservation and economic importance. At sea, individuals typically are subject to sea lice infestation, which can have detrimental effects on their host. Over recent decades, the body condition and marine survival in NE Atlantic stocks have generally decreased, reflected in fewer adults returning to rivers, which is partly attributable to sea lice. We developed a deterministic stage-structured population model to assess condition-mediated population dynamics resulting in changing fecundity, age at sexual maturation and marine survival rate. The model is parameterized using data from the North Esk system, north-east Scotland. Both constant and density-dependent juvenile survival rates are considered. We show that even small sea lice-mediated changes in mean body condition of MSW can cause substantial population declines, whereas $1 \mathrm{SW}$ condition is less influential. Density dependence alleviates the condition-mediated population effect. The resilience of the population to demographic perturbations declines as adult condition is reduced. Indirect demographic changes in salmonid life-history traits (e.g., body condition) are often considered unimportant for population trajectory. The model shows that Atlantic salmon population dynamics can be highly responsive to sea lice-mediated effects on adult body condition, thus highlighting the importance of non-lethal parasitic long-term effects.

KEYWORDS

Atlantic salmon, matrix model, non-lethal effect, population dynamics, sea lice, stage-structured population
\end{abstract}

\section{1 | INTRODUCTION}

Atlantic salmon Salmo salar is an iconic species with high cultural and economic value (e.g., Gardner Pinfold 2011). Its natural range stretches across temperate and subarctic regions of the Atlantic Ocean. Most populations are anadromous, and juveniles (alevins, fry, parr) rear in freshwater for one or more years (Webb, Verspoor, Aubin-Horth, Romakkaniemi, \& Amiro, 2007), before parr transform to smolts and migrate to marine feeding grounds. In freshwater, the population is regulated through one or more density-dependent factors such as intra- and interspecific competition for resources (e.g., food, shelter, spawning grounds), predation and infection rates (Jonsson, Jonsson, \& Hansen, 1998). Accordingly, the egg-smolt survival rate decreases as density of deposited eggs increases (Chaput et al., 1998). There is no evidence of density dependence at sea (Jonsson et al., 1998), where individuals spend one or more winters before maturation triggers a return migration to their natal rivers for reproduction as one-sea-winter grilse (1SW) or multi-sea-winter salmon (MSW) (Webb et al., 2007). 
There has been a general decline in Atlantic salmon populations in both North American and European stock complexes since the 1970s (ICES 2015) thought to be primarily driven by decreased survival during the marine phase (Jonsson \& Jonsson, 2004). This decline in marine survival has been accompanied by a reduction in body condition of $1 \mathrm{SW}$ and MSW in major Scottish salmon populations (Bacon et al., 2009), and is thought to be related to climate and ecosystem modifications in both freshwater (McCormick et al., 2009) and marine habitats (Friedland et al., 2009; Smith et al., 2011; Todd et al., 2008). In addition to a direct impairment of salmonid physiology, these habitat modifications can indirectly increase the impact from predators, pathogens and parasites such as sea lice (Lepeophtheirus salmonis and Caligus spp), as well as cause declines in abundance and quality of prey. Predators, parasitic sea lice and pathogens alone or in combination can increase mortality (Marino \& Werner, 2013). Sea lice have non-lethal physiological consequences such as increased stress, reduced growth rate and ultimately condition (e.g., Finstad, Bjørn, Grimnes, \& Hvidsten, 2000; Tveiten, Bjørn, Johnsen, Finstad, \& McKinley, 2010). Condition in Atlantic salmon is closely correlated with lipid stores (Todd et al., 2008) and is assumed to represent individual fitness. Salmon in poor condition are less fecund (Burton, McKelvey, Stewart, Armstrong, \& Metcalfe, 2013b), mature later (e.g., Reimers, Kjorrefjord, \& Stavostrand, 1993; Thorpe, Talbot, Miles, \& Keay, 1990) and produce offspring with impaired fitness (Burton, McKelvey, Stewart, Armstrong, \& Metcalfe, 2013a; Todd et al., 2012).

Proximity to salmon aquaculture and associated sea louse infestation pressure have been demonstrated to reduce weight in wild sea trout Salmo trutta post-smolts by up to $9 \mathrm{~g}$ (at average length of $18 \mathrm{~cm}$ ), thus reducing Fulton's condition factor by ca. 0.15 (Shephard, Maclntyre, \& Gargan, 2016). Tveiten et al. (2010) reported that experimental infestation of adult Arctic charr Salvelinus alpinus reduced host condition by up to 0.25 . Some studies found no clear effect from sea lice infestation on salmonid condition: Murray \& Simpson (2006) concluded that the length-weight relationship in adult Atlantic salmon carrying either 0 or $>10$ (mobile) sea lice was alike. Todd, Whyte, MacLean, and Walker (2006) reported no correlation between salmon condition factor and abundance (sea lice per fish) of the two parasite species pooled, or of L. salmonis alone. However, the authors found a positive correlation between C. elongatus abundance and condition, which was likely caused by a dependence of both parasite abundance and condition factor on host mass. Similarly, MacKenzie, Longshaw, Begg, and McVicar (1998) found equivocal (positive and negative) correlations between some parasite stages and condition in sea trout. However, these studies used parasite abundance (sea lice host ${ }^{-1}$ ) instead of density (sea lice $\mathrm{kg}^{-1}$ ) as infestation parameter, therefore disregarding the dependence of a potential condition effect on host size.

Despite salmon being a relatively well-studied species, there are substantial gaps in our knowledge of Atlantic salmon population biology and potential responses to parasite interaction. This is mainly due to a complex and flexible life history featuring highly divergent strategies within and between populations. Thus, modelling Atlantic salmon populations is potentially challenging, but provides a useful method to assess population responses to changes in vital rates and management strategies. Accordingly, a variety of group-based models (GBMs) where the population is split into categories with identical individuals (ages or stages) have been applied in Atlantic salmon populations. For example, matrix models were used to determine the contribution of different life stages to population growth and to examine whether natural selection causes increasing precocious male parr maturation in a Canadian stock (Caswell, Naiman, \& Morin, 1984). Browne (1988) used a Leslie matrix to investigate an Irish stock and conducted a simple perturbation analysis. des Clers (1993) modelled Atlantic salmon in Scotland using differential equations to assess the impact of disease-induced mortality. However, these models assumed constant demographic parameters. Others introduced stochasticity and density dependence to perform a population viability analysis (PVA) (Legault, 2004, 2005) or life stage simulation analysis (LSA) (Robertson, 2005) accounting for uncertainties and demographic rate variability. In contrast to GBMs, various individualbased models (IBMs) have been developed for Atlantic salmon (e.g., Castellani et al., 2015; Piou \& Prévost, 2012). Such models account for variability within a population category by allowing the representation of individual traits. Such a detailed implementation potentially increases the predictive power of the model at the cost of structure complexity. Parameterization of IBMs is data intensive, with the required sample size necessary to fully accommodate the potential model variability being rarely attainable owing to computational and processor limitations.

Here we aim to determine how sea lice-mediated changes in the condition of adult individuals can affect the long-term dynamics of Atlantic salmon populations. To do so, we developed an Atlantic salmon condition-mediated population model which incorporates condition-dependent fecundity (eggs per female), sexual maturation and marine survival (smolt return rate), as well as a density-dependent egg-to-smolt survival rate. We therefore address for the first time how indirect effects of condition challenges during the marine phase could alter population trajectory in Atlantic salmon.

\section{MATERIALS AND METHODS}

We modelled stage transitions during the Atlantic salmon life cycle (Figure 1, Tables 1 and S1). In this first instance, we developed a deterministic model, which can be easily extended to account for stochasticity. The model was parameterized using estimates characteristic for the River North Esk stock, north-east Scotland, where possible. Parameters unavailable for this system are based on estimates from the whole of Scotland (maturation probability after one sea winter, home water exploitation rate, adult female proportion), Ireland (fecundity) and the whole of Great Britain (constant eggsmolt survival rate). The model is tested with two different regulatory recruitment scenarios: (i) a constant egg-smolt survival rate resulting in unrestricted population growth and (ii) egg-smolt survival rate decreasing with egg density via a Beverton-Holt function. To 


\section{Freshwater phase Marine phase}

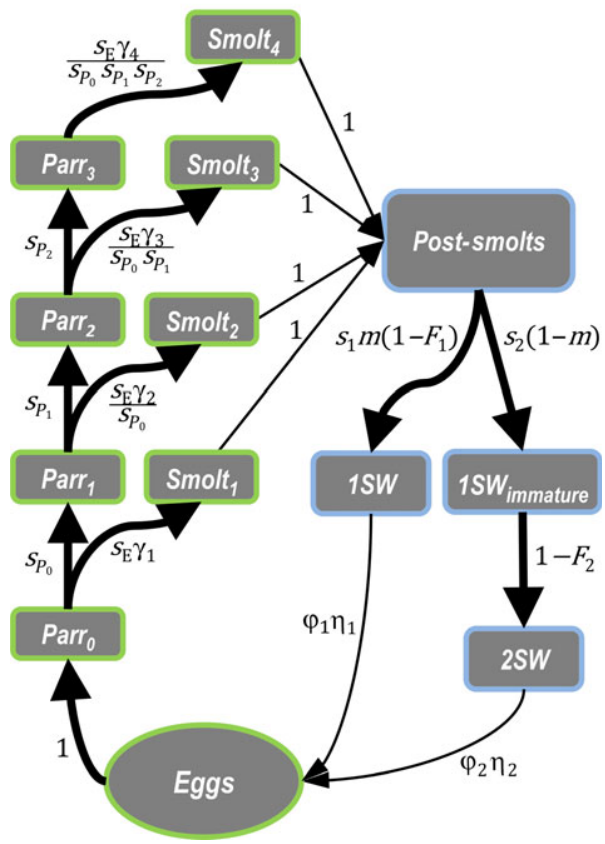

FIGURE 1 Life cycle for Atlantic salmon with up to four juvenile years (parr) and one (1SW) or two (2SW) sea winters. All eggs spawned by $1 S W$ and $2 S W$ females ( $\varphi$ : female ratio, $\eta$ : fecundity) hatch next year and become Parro. Subsequently, parr can either remain in freshwater ( $s_{P}$ : parr survival rate) or transform and migrate to sea as smolts ( $s_{\mathrm{E}}$ : egg-smolt survival rate, $\gamma$ : smoltification likelihood). At sea, all smolts become post-smolts which turn 1SW after their first sea winter. 1SW fish can either maturate $(m)$ and return for reproduction same year (1SW) or remain at sea for another year, thus returning and reproducing as 2SW fish (s: natural mortality at sea plus potential distant-water exploitation, $F$ : natural mortality and human exploitation in freshwater). Bold arrows indicate a transition in time (by 1 year)

obtain a useful initial system, the egg-smolt survival rate in scenario I was permanently tuned from $0.8 \%$ to $1 \%$. In scenario II, for the model to produce spawner numbers similar to actually estimated numbers in the North Esk, the maximum possible recruit (smolts) output had to be tuned from 248,000 to 300,000 .

\section{1 | Model description and parameterization}

\subsubsection{Freshwater phase}

As the North Esk salmon stock contains few (typically $<1 \%$ ) repeat spawners or salmon spending 3 or more winters at sea (Gurney, Bacon, Malcolm, MacLean, \& Youngson, 2015), these groups are ignored in the present work. Thus, all fish in the model return from sea as 1SW (sea-age $a=1)$ or 2SW $(a=2)$ and spawn in the same year. The female proportion $\varphi_{a}$ for each $a$ was assumed constant and based on estimates used by Marine Scotland Science (Anon 2015). Female $1 S W$ and $2 S W$ monthly mean wet weights $\left(w_{a}\right)$ were set at 2.15 and $4.85 \mathrm{~kg}$, based on samples from North Esk estuary in
2001, 2002, 2003, 2014 and 2015 (April to August), with the associated fork length $\left(L_{a}\right)$ of 58.4 and $75.2 \mathrm{~cm}$. These values can vary in fish running off-season (before April or after August); however, owing to lack of according data, these weight and length values are assumed to be representative for the whole spawning cohort. The term "default" (denoted as subscript "d") will be used throughout the text to refer to these original fish weight values $\left(w_{a}=w_{a_{\mathrm{d}}}=(2.15,4.85) \mathrm{kg}\right)$ and resultant parameter values such as fecundity, body condition and marine survival.

For both $1 \mathrm{SW}$ and $2 \mathrm{SW}$, individual fecundity $\eta_{a}$ (eggs per female) is given as a function of $\mathrm{w}_{a}$ via the model described by de Eyto et al. (2015) for Irish Atlantic salmon sampled between 1992 and 2012 (Equation 1, Fig. S1), which is assumed to be representative for Scottish salmon:

$$
\eta_{a}=e^{\left(7.45+0.28 w_{a}\right)}
$$

The number of eggs $E$ spawned in year $t$ is the product of male and female spawner abundance $N_{a, t}$, individual fecundity $\eta_{a}$ and female proportion $\varphi_{a}$ :

$$
E_{t}=N_{1, t} \eta_{1} \varphi_{1}+N_{2, t} \eta_{2} \varphi_{2}=\sum_{a=(1,2)} N_{a, t} \eta_{a} \varphi_{a}
$$

All eggs hatch, develop to fry and subsequently parr $(P)$ stage $0\left(P_{0}\right)$ over the following year $(t+1)$. $P_{0}$ surviving year $t+1$ can either remain parr in the following one, two or three years (becoming $P_{1}, P_{2}$ or $P_{3}$ ), or undergo smoltification instead, thus becoming smolts or recruits $(R)$ of river-age one, two or three $\left(R_{1}\right.$, $R_{2}$ or $R_{3}$ ) in years $t+2, t+3$ or $t+4$, respectively. The population has a maximum river-age of 4 years (Todd et al., 2012). Thus, all $P_{3}$ which survive year $t+4$ will undergo smoltification and become $R_{4}$ in year $t+5$. The parr survival rates $\left(s_{P_{j}}\right)$ from $P_{j}$ to $P_{j+1}$ with $j=\{0,1,2\}$ applied are constants based on estimates reported by Bley and Moring (1988) for Great Britain. However, as these estimates may be unrepresentative as they (i) might be out of date, (ii) were derived for hatchery fish and (iii) have high variability, a direct transition from eggs to smolts is raised. The parr stages with according survival rates $s_{P_{j}}$ were nevertheless retained to facilitate easy handling of overlapping freshwater stages for life-history maintenance. Thus, as smolts are modelled directly as a function of spawned eggs (from which the smolts emanate) (see Equations 4 and 5), the parr stages do not affect the population dynamics in any way, but do provide a more realistic juvenile stage structure.

Accordingly, the number of smolts $R_{i, t+1+i}$ of river-age $i=\{1, \ldots$, 4) resulting from $E_{t}$ is determined directly via the egg-smolt survival rate $s_{E, t}$. For comparison, two different regulatory scenarios are tested:

Scenario I: constant $s_{E, t}$ of $1 \%$ based on estimates for Great Britain by Hutchings and Jones (1998), resulting in a linear demographic model with exponential population growth;

Scenario II: density-dependent $s_{E, t}$ as a function of the egg cohort $E_{t}$ (stock) from which smolts $R_{i, t+1+i}$ (recruits) will descend, using a 
TABLE 1 Variable (top) and constant parameters (bottom) used for scenario I (constant $s_{\mathrm{E}}$ ), scenario II (density-dependent $s_{\mathrm{E}}$ ) or both. Values of constants and defaults of variables (i.e., at default $w_{a}$ ) are shown in the right column(s)

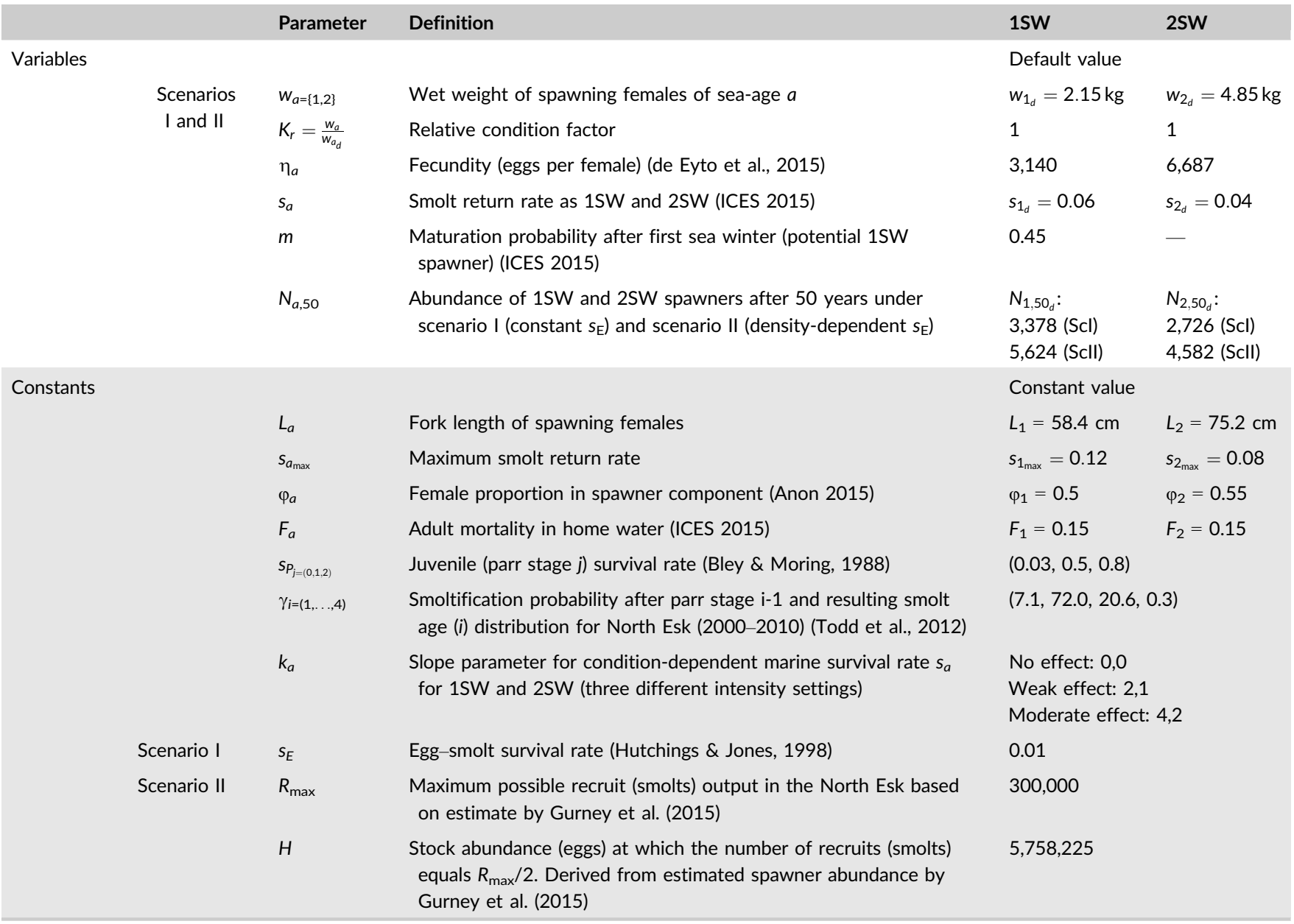

Beverton-Holt type stock-recruitment model (SR) (Equation 3, Fig. S2) with parameters $R_{\max }$ (max. recruit output (smolts)) and $H$ ( $E_{t}$ at which the number of recruits equals $R_{\max } / 2$ ) adopted from Gurney et al. (2015, p. 48) for North Esk salmon (based on parameters estimated if whole stock ( $1 \mathrm{SW}$ and $2 \mathrm{SW}$ ) were treated as a single stock, with grilse error correction applied (see Gurney et al., 2015 for details).

As the SR by Gurney et al. (2015) uses spawner abundance (instead of eggs) as stock, we adjust the model accordingly by applying a spawner-to-egg conversion (based on Equation 2: each spawner $=\bar{\eta}_{a} * \bar{\varphi}_{a}$ ). The recruit (smolt) number is given as:

$$
\sum_{i=\{1, \ldots, 4\}} R_{i, t+1+i}=\frac{R_{\max } * E_{t}}{E_{t}+H}
$$

As our matrix model works with survival rates, we convert Equation (3A) to an egg-smolt survival rate:

$$
s_{E, t}=\frac{\sum_{i=\{1, . ., 4\}} R_{i, t+1+i}}{E_{t}}=\frac{R_{\max }}{E_{t}+H}
$$

The river-age composition of smolts is determined by a fixed probability distribution $\gamma_{i}$ which allocates a likelihood of becoming a smolt of river-age $i=(1, \ldots, 4), \gamma_{i}$ was based on the river-age composition of the emigrant North Esk smolt cohort between 2000 and 2010 of 7.1, 72, 20.6, 0.3\% (Todd et al., 2012).

Thus, abundance of smolts $R_{i, t+1+i}$ emerging from $E_{t}$ is given as:

$$
R_{i, t+1+i}=E_{t} S_{E, t} \gamma_{i}
$$

However, the projection matrix incorporates interjacent parr stages with according survival rates $s_{P_{j=(0,1,2)}}$ between egg and smolt stages. Thus, smolts are de facto determined from preceding parr stages, which are less abundant than eggs (unless $s P_{j=(0,1,2)}=1$ ). Accordingly, introduced parr mortality in the matrix was accounted for by adjusting the number of smolts, with older smolts affected more owing to a cumulative mortality from all preceding parr stages (for further details, see Figure 1 and Table S1):

$$
R_{i, t+1+i}^{*}=\frac{E_{t} s_{E, t} \gamma_{i}}{\prod s_{P_{j \leq i-2}}}
$$

\subsection{2 | Marine phase}

Smolts $R_{i, t+1+i}$ entering the sea in $t+1+i$ are termed post-smolts. After the first sea winter, all post-smolts become 1SW in $t+2+i$ 
(post-smolt mortality is implied in overall marine survival s). A proportion of these gains maturity $(m)$ and survivors $\left(s_{1}\right)$ return to freshwater as $1 \mathrm{SW}$ spawners in the same year. The non-maturing $(1-m)$ 1SW component remains at sea for another year, so that survivors $\left(s_{2}\right)$ return as $2 \mathrm{SW}$ spawners in $t+3+i$. Mean return rates of wild smolts between 2000 and 2010 to the North Esk reported by ICES WGNAS (2015 p. 98) are used as default values $s_{a d}$. The default maturation rate $m_{d}$ is based on recent ICES estimates for Scotland (ICES 2015 p. 139). However, $m$ is catchmentspecific and driven by complex genetic and environmental interactions which remain largely unknown. Thus, we arbitrarily assume a linear relationship between $m$ and maturing post-smolt body condition (using 1SW spawner condition $\left(K_{r, 15 W}\right)$ as a proxy) (see Fig. S4):

$$
m=m_{\mathrm{d}} * K_{r, 1 \mathrm{sw}}
$$

Thus, if body condition in the post-smolt cohort increases, a greater proportion of post-smolts is able to gain maturity and return as 1SW spawners (as opposed to 2SW spawners).

Back in freshwater, returning $1 \mathrm{SW}$ and $2 \mathrm{SW}$ are subject to natural mortality and human exploitation (aggregated as $F_{a}$ ), and surviving fish will reproduce in the same year they returned. $F_{a}$ is implemented as a constant derived from current ICES figures (ICES 2015 p. 128).

\subsection{Condition factor}

The relative condition factor $K_{r}$ is used as a proxy for individual fitness and given as the proportion between the observed individual fish wet weight $w_{a}$ and the default weight $w_{a_{d}}=\varepsilon L_{a}{ }^{\delta}$ expected at default fork length $L_{a}$. Constants $\varepsilon$ and $\delta$ are dispensable parameters of the weight-length relationship in the population:

$$
K_{r}=\frac{W_{a}}{W_{a d}}=\frac{W_{a}}{\varepsilon L_{a}^{\delta}}
$$

$K_{r}$ can be modified via a change in $w_{a}$ at constant $L_{a}$. Thus, the denominator in Equation 7 remains constant, so that $K_{r}$ and $w_{a}$ are directly proportional:

$$
K_{r} \propto w_{a}
$$

This means that a change in $w_{a}$ in the simulations by any factor is synonymous with a change in $K_{r}$ by the same factor. The simulations presented cover a $w_{a}$ range deviating by factor \pm 0.1 from its default value $w_{a_{d}}$, which is equivalent to a $K_{r}$ ranging from 0.9 to 1.1. This range is an assumption based on the work by Tveiten et al. (2010) on experimentally exposed Arctic charr. Mean of 70 sea lice $\mathrm{kg}^{-1}$ reduced condition factor in adult fish by up to mean 0.1. Empirical observations of returning wild Atlantic salmon from northern Scotland have shown that naturally observed infestation abundances range from 4 to 152 (median 37) mobile sea lice per fish (Todd et al., 2006) alongside a grand mean weight of $2.34 \mathrm{~kg}$. This corresponds to a range of 1.7-65 (median 15.8) sea lice $\mathrm{kg}^{-1}$. Assuming a similar response in salmon as Arctic charr to sea lice $\mathrm{kg}^{-1}$, we explore a similar effect range up to 0.1 .

\subsection{Condition effect}

In addition to affecting fecundity $\eta_{a}$ (Equation 1) and maturation rate $m$ (Equation 6), adult $K_{r}$ has a potential effect on marine survival $s_{a}$. The actual effect is unknown and was modelled using three different settings: (A) no effect, (B) weak effect and (C) moderate effect (Equation 8, Fig. S3). These relationships were chosen based on the consideration that Atlantic salmon can be categorized as capital breeders (Jager, Rose, \& Vila-Gispert, 2008), that is, resources invested in offspring originate from endogenous energy stores accumulated earlier at sea. This enables the mobilization of stored energy under potentially lethal environmental conditions, enabling individuals to compensate at the cost of body mass and accordingly body condition. Therefore, $s_{a}$ is assumed to remain relatively unaffected as $K_{r}$ changes, and is modelled as a function of female weight $w_{a}$ using a logistic function:

$$
s_{a}=\frac{s_{a_{\max }}}{1+e^{-k_{a}\left(w_{a}-w_{a_{\mathrm{d}}}\right)}}
$$

$S_{a_{\max }}$ is the approximate maximum smolt return rate observed in the North Esk (ICES 2015), which for each sea-age is twice the default rate $s_{a_{\mathrm{d}}}$. Such a parameterization warrants the correctness of the applied marine survival rates, so that $s_{a_{\mathrm{d}}}$ are assigned to fish of default weight (i.e., $w_{a}=w_{a_{d}}$ ). Arbitrarily chosen constants $k_{a}$ determine the intensity (according to settings $A-C$ ) of the condition effect on $s_{a}$. Intensity increases with increasing $k_{a}$ (Fig. S3).

\section{4 | Initial population}

The same initial population structure is used for every simulation to enable comparison between different parameterizations. It was determined using the stable stage distribution (stable.stage function in R-package popbio (Stubben \& Milligan, 2007)) of the population under scenario I (constant $s_{E}$ ) with default adult weights $w_{a_{\mathrm{d}}}$, multiplied by $10^{7}$ and rounded to the nearest hundred (Table 2).

\section{5 | Model analysis and Interpretation}

A homogenous population (identical individuals within each stage) is assumed, allowing for modifications of body condition $K_{r}$ of $1 \mathrm{SW}$

\begin{tabular}{|c|c|c|c|c|c|c|c|c|c|c|c|}
\hline Life stage & Eggs/fry/Po & $P_{1}$ & $P_{2}$ & $P_{3}$ & $R_{1}$ & $R_{2}$ & $R_{3}$ & $R_{4}$ & $1 S W$ & 1SW (immature) & $2 S W$ \\
\hline Abundance $N$ & $9,376,700$ & 278,600 & 137,900 & 109,300 & 6,500 & 66,100 & 18,900 & 300 & 2,100 & 2,000 & 1,700 \\
\hline
\end{tabular}
and $2 S W$ spawners. Dictating fecundity $\eta_{a}$, maturation $m$ and marine survival rates $s_{a}$, the effect of $K_{r}$ on the population is assessed.

TABLE 2 Starting population used for all simulations 
Scenarios I and II (constant or density-dependent $s_{E}$ ) are compared, allowing for marine survival rates $s_{a}$ to be either (A) not at all, (B) weakly or (C) moderately influenced by $K_{r}$. As $1 \mathrm{SW}$ and $2 \mathrm{SW}$ are subject to spatially and temporally different prevailing marine environmental conditions, the influence of each sea-age class $a$ on population dynamics is assessed individually. Thus, $K_{r}$ is modified in 1SW only, $2 \mathrm{SW}$ only or both.

Comparing 1SW and 2SW spawner abundance at the end of each 50-year simulation $\left(N_{a, 50}\right)$ allows for an assessment of the relative effect of each manipulation in $K_{r}$. For scenarios I and II individually, $N_{a, 50}$ obtained applying the default weight parameters $w_{a_{d}}$ (i.e., $K_{r}=1$ ) was considered as the default abundance $N_{a, 50_{d}}$ of each seaage $a$, and set as a baseline value of 1 . The spawner abundance $N_{a, 50}$ resulting from simulations with altered $K_{r}$ is described as proportion of this default abundance, that is, $N_{a, 50} / N_{a, 50_{d}}$.

We also estimated the population resilience under different $K_{r}$ in scenario II. We estimated engineering resilience (Holling, 1996) as the number of years the starting population requires to approach its equilibrium, that is, when population growth rate $\lambda$ stabilized.

The stable stage distribution is determined and an elasticity analysis (stable.stage and elasticity functions from the R-package popbio (Stubben \& Milligan, 2007)) conducted for recruitment scenarios I and II using default parameters (at stable stage $(t=100)$ for scenario II).

\section{3 | RESULTS}

Using default parameters, the $1 \mathrm{SW}$ and $2 \mathrm{SW}$ spawner abundance after 50 years reaches $N_{1,50_{d}}=3,379$ and $N_{2,50_{d}}=2,726$ under scenario I (constant $s_{E}$ ), and $N_{1,50_{d}}=5,624$ and $N_{2,50_{d}}=4,583$ under scenario II (density-dependent $s_{E}$ ). The abundance in scenario II is close to actual spawner abundance estimates (Gurney et al., 2015). It is higher than in scenario I due to an initially higher eggsmolt survival rate before approaching carrying capacity. These default spawner abundances were each adjusted to 1 (baseline) to enable relative comparisons between varying model parameters.

\subsection{Elasticity analysis and stable stage distribution}

The elasticity values in the matrix model were basically identical for both scenarios I and II (Figure 2, showing only scenario I). The viability of the Atlantic salmon population is most susceptible $(\sim 0.19)$ to changes in the survival rate during the first year $s_{P_{0}}$ (eggs, fry, young-of-theyear), that is, Parr $_{0}$ to Parr 1 . Transition to smolts of river-age 2, that is, Parr $_{1}$ to Smolt 2 , provides the majority of elasticity in the smolt stage, as this is by far the most prevalent smolt stage in the population ( $70 \%$ ). However, all transitions and according elasticities during the freshwater stage are represented by the egg-smolt survival rate $s_{E}$ and smoltification likelihood $\gamma_{i}$. 2SW are more important $(\sim 0.14)$ than 1 SW $(\sim 0.07)$.

The stable stage distributions are also very similar for both scenarios (Figure 3). Egg abundance $E$ (equal to fry or Parro abundance) in scenarios I and || contributed 93.77 and $93.71 \%$ of the total

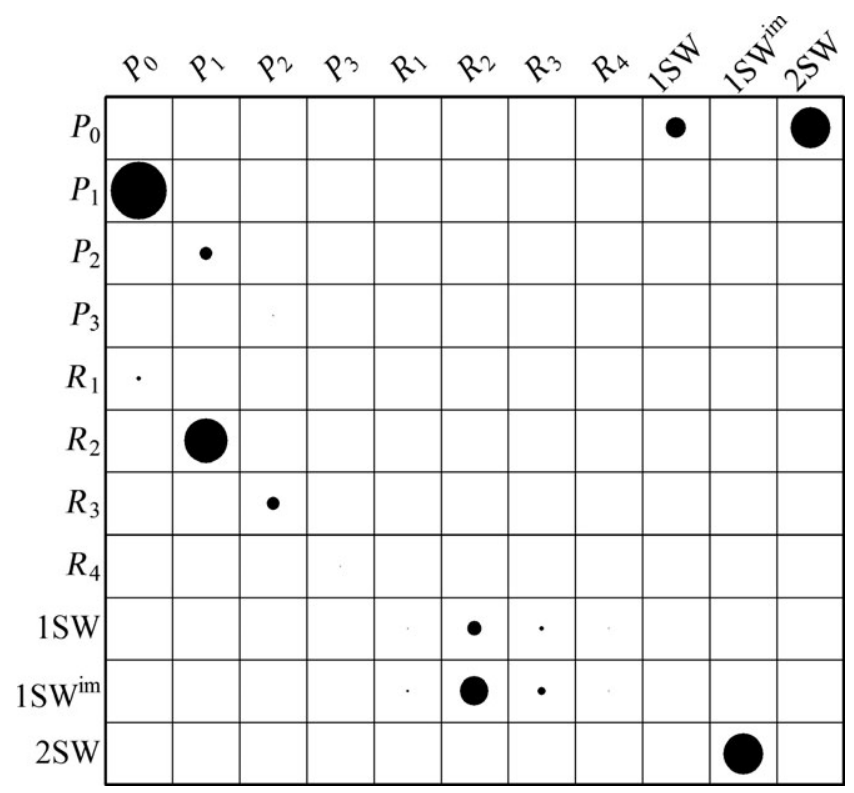

FIGURE 2 Dots depicting elasticity values (proportional to dot size) for each stage transition of the matrix model with default parameters, assuming constant (scenario I) or density-dependent (scenario II) egg-smolt survival rate. $P$ stands for parr and $R$ for smolt stages. Transition direction is from columns to rows (e.g., $P_{1}$ becomes $P_{2}$ or $R_{2}$; and $R_{2}$ becomes $1 \mathrm{SW}$ spawners (1SW) or remains immature $1 \mathrm{SW}$ fish $\left(1 S W^{\mathrm{im}}\right)$ ). Bigger dots indicate stages with more influence on population performance

populations, respectively, and is not shown in the histograms. The sum of $1 \mathrm{SW}$ and $2 \mathrm{SW}$ spawners in each scenario constituted less than $0.04 \%$.

\subsection{Condition effect}

The condition effect is mainly driven by the influence from $K_{r}$ on marine survival $s_{a}$ (Figure 4 , solid vs. dashed vs. dotted lines) and is generally more pronounced if condition $K_{r}$ in both $1 \mathrm{SW}$ and 2SW is altered simultaneously (Figure 4, top row). In scenario I, the condition-mediated effect increases exponentially due to the exponential function of population growth (Figure 4, left). In scenario II on the other hand, density dependence drastically compensates for the influence of $K_{r}$ on population dynamics, and thus, the effect changes linearly (Figure 4, right); for example, assuming a reduction in $K_{r}$ by $5 \%\left(w_{1}=2.043 \mathrm{~kg}, w_{2}=4.608 \mathrm{~kg}, K_{r}=0.95\right)$ in both $1 \mathrm{SW}$ and $2 \mathrm{SW}$ with $K_{r}$ "moderately" affecting marine survival (setting C): in scenario I, the relative $1 \mathrm{SW}$ and $2 \mathrm{SW}$ spawner abundance after 50 years drops below 0.05 each (corresponding to $1311 \mathrm{SW}$ and 247 2SW) (Figure 4 left, top row, dotted curves). In scenario II however, this drastic impact is dampened and the relative spawner abundance declines to about 0.69 and 0.73 , corresponding to 3,873 1SW and 3,343 2SW, respectively (Figure 4 right, top row, dotted curves).

In scenario I, the $2 \mathrm{SW}$ component alone (Figure 4, left bottom row) is more influential than the $1 \mathrm{SW}$ component (Figure 4, left middle row), whereas in scenario II changes in condition of $2 \mathrm{SW}$ alone 

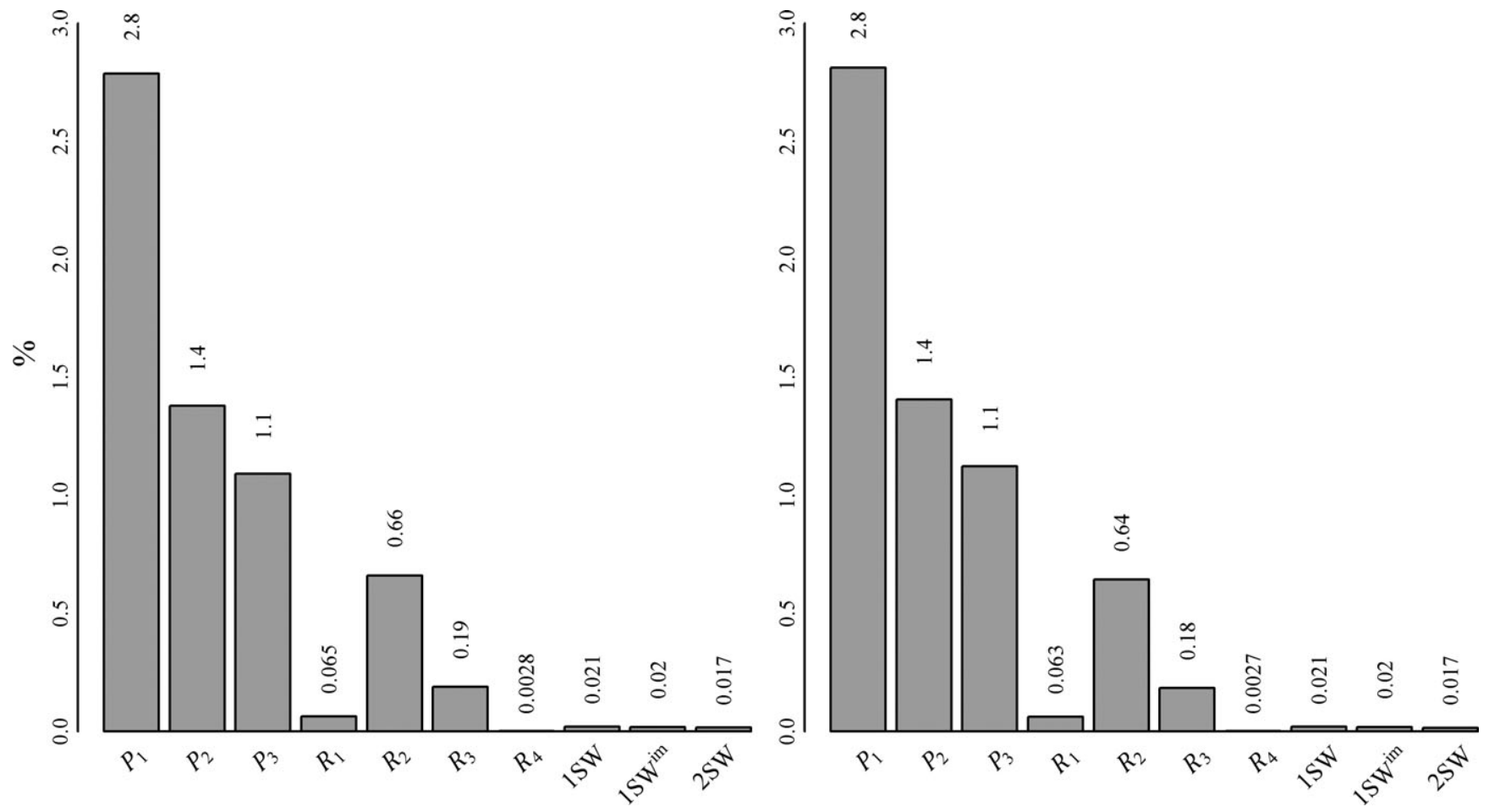

FIGURE 3 Stable stage distribution (\%) of the population using default parameters assuming constant (scenario I, left) or density-dependent (scenario II, right) egg-smolt survival rate. $P$ stands for parr and $R$ for smolt stages. In each scenario, $P_{0}$ (eggs/fry/Parro) contribute over $93 \%$ and are excluded from the histograms

have little effect on dynamics of 1SW, and vice versa. Conditiondependent (1SW) maturation considerably influences the $1 \mathrm{SW} / 2 \mathrm{SW}$ ratio and thus the stable structure of the spawning cohort.

Population resilience is also influenced by $K_{r}$ of the spawning cohort. If $K_{r}$ is low, the population requires longer to stabilize (i.e., population growth rate $\lambda$ (always $\geq 1$ ) declines to $\sim 1$ ) (Figure 5 ). However, the resilience variation between different settings is low, and in any simulation, the population typically reached stable state after 14 to 16 years.

\section{4 | DISCUSSION}

Our results demonstrate that condition-mediated life-history parameters (fecundity, sexual maturation and survival at sea) in Atlantic salmon can be major drivers of modelled population dynamics, changing long-term stock size and structure, as well as resilience. Density-dependent juvenile survival has a strong stabilizing effect on the dynamics of the model population by exerting a negative feedback at increasing egg deposition. As a result, the shown changes in spawner abundance as response to changing spawner condition under scenario II are dampened and far less intense than in scenario I (Figure 4). Owing to a relatively high female proportion and fecundity, the 2SW class is about two times more important for stock viability than $1 \mathrm{SW}$.

The life cycle of Atlantic salmon is complex, and demographic rates between and within river systems can have large variation as each population has adapted to unique conditions (Verspoor et al., 2005). We developed a condition-mediated population matrix model to assess population performance under different environmental scenarios which can possibly also be used to gain insight into the direction and intensity of natural selection on life-history traits (via sensitivity values of the population growth rate $\lambda$ ) (Caswell, 2001, Section 11). The model was tuned using parameter estimates drawn from observations of the River North Esk stock in north-east Scotland, where possible, as this catchment has been well studied over a long period. Results are based on a deterministic model with identical individuals in each life stage set in a constant environment. This theoretical model does not readily apply to any particular stock, and given the static nature of its parameters, the stock abundance estimated after 50 years is useful only in a relative manner, as assumed constant parameters can change over this period. Nevertheless, the model provides relative estimates of population sensitivity to condition factor perturbation, highlighting the qualitative influences of changes and depicting potential traits underlying selective pressure.

The effect from changes in spawner condition was measured as spawner abundance after a simulation period of 50 years. This simulation period was chosen arbitrarily with the intention to allow the population under scenario II (density dependence) enough time to approach a stable state. The population usually stabilized after only 14 to 16 years (Figure 5). This period is a measure of population resilience and generally was shorter if adults in the stock were in better condition. Thus, non-lethal effects can be important for the ability of a population to recover from perturbation. Because the 


\section{Scenario I: Constant}
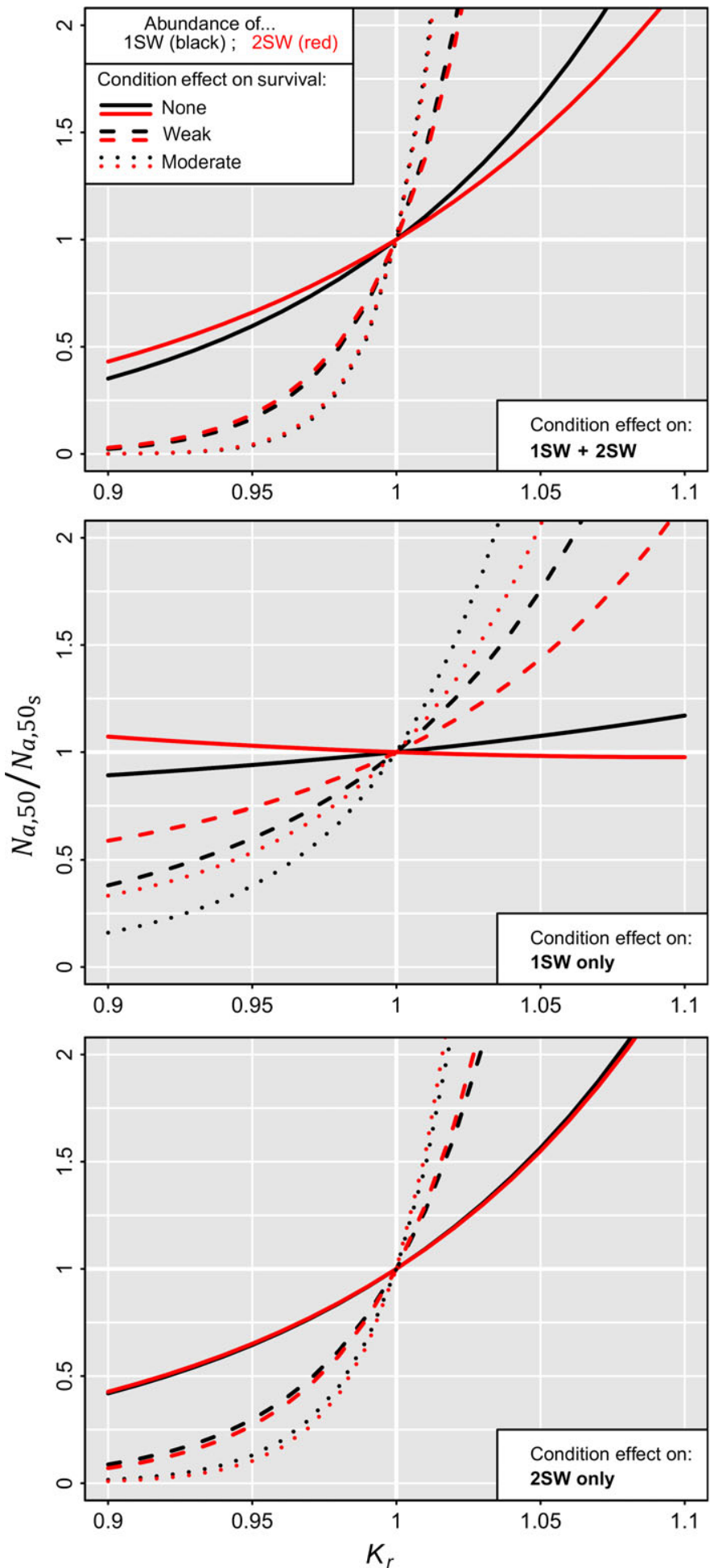

Scenario II: Density-dependent
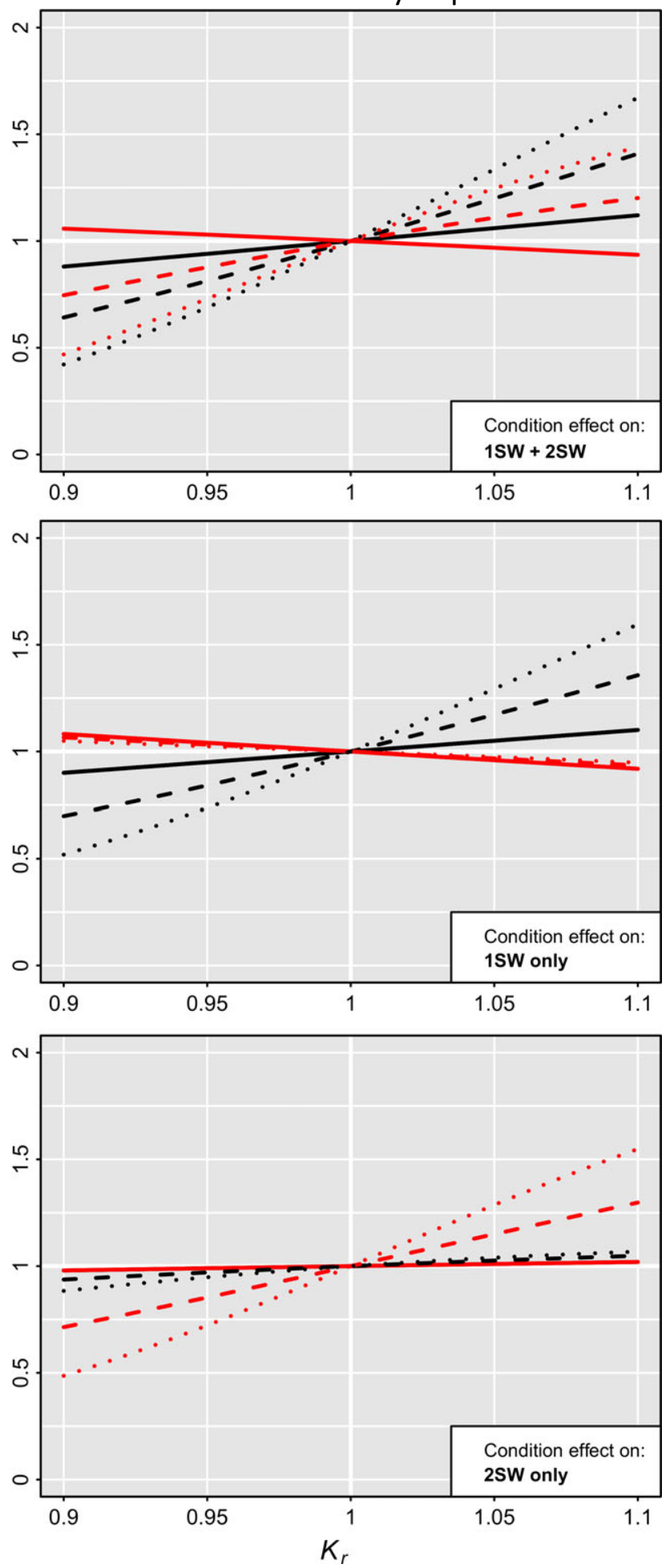

FIGURE 4 Relative $1 \mathrm{SW}$ (black) and 2SW (red) spawner abundance after a period of 50 years $\left(\mathrm{N}_{a, 50} / \mathrm{N}_{a, 50_{d}}\right)$ as a function of spawner condition $K_{r}$. Spawner abundance obtained using default parameters $\left(K_{r}=1\right) . N_{a, 50}$ is adjusted to 1 . Egg-smolt survival rate is assumed constant (scenario I, left) or density-dependent (scenario II, right). Changes in $K_{r}$ can affect $1 \mathrm{SW}$ (middle row), 2SW (bottom row) or both (top row)

population reached equilibrium before the end of the simulation (50 years), the reported condition effect on spawner abundance under scenario II (Figure 4, right) was also fully pronounced after only 14 to 16 years. In the population with unrestricted population growth (scenario I) on the other hand, the intensity of this effect increases with the simulation period. Thus, the disparity in 

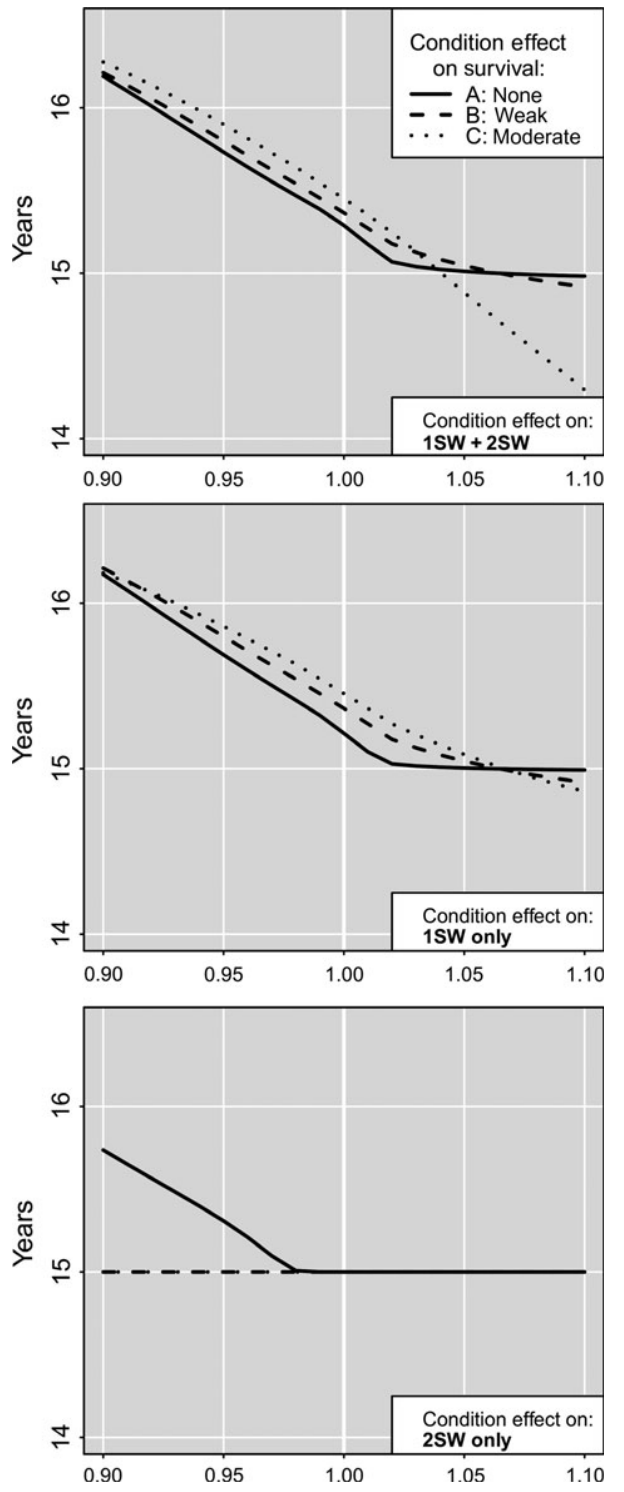

FIGURE 5 Resilience (years required to approach stable state [yaxis]) as function of spawner condition $K_{r}$ (x-axis). $K_{r}$ is presumed to affect 1SW (middle), 2SW (bottom) or both (top), according to condition factor effects on survival being set to no effect, weak or moderate effect

population response to condition modifications between scenarios I and II generally increases with the simulation duration.

For both constant and density-dependent scenarios, the elasticity analysis revealed that population viability is highly sensitive to survival during the freshwater phase (egg to smolt), which is consistent with Robertson (2005) (Figure 2). The reason for the importance of the freshwater phase is because it is the larger part (up to 4 years) of the salmon life history, during which individuals are subject to comparably high mortality rates. And while reduced survival at sea appears the major determinant of declining stocks, the availability of suitable freshwater habitat is vital to maintain smolt numbers to mitigate marine mortality (Russell et al., 2012). The relative importance of 2 SW fish to population performance reported here is consistent with results obtained by des Clers (1993). As spawner fecundity applied in the model (Irish populations) increases with weight at a similar rate in populations, for example, in Canada, Norway or Finland (Fig. S1), the relative importance of $2 \mathrm{SW}$ fish (or MSW fish in general) is likely pronounced in many populations across the species' range. In view of the crucial contribution of $2 \mathrm{SW}$ individuals to stock performance in our model, the decline of this particular component in the American and South European stock complexes (ICES 2015) is concerning.

\subsection{Assumptions and limitations}

Owing to gaps in knowledge about certain life-history traits, the parameterization of the model has limitations. Primarily, we do not know how body condition of individual salmon returning from sea is reflected in their chance to survive the preceding marine phase, as all sampled fish are survivors. We assume, however, that the mean condition factor of a returning cohort is correlated with its survival rate at sea. Thus, the proposed relationships were chosen to cover a certain range without overvaluing the condition effect on survival and to be similar for $1 \mathrm{SW}$ and 2SW (Fig. S3). Furthermore, owing to lack of data, female fecundity is derived from wet weight assuming constant fish length, instead of actual body condition. This may lead to underestimation of the actual condition effect on fecundity. However, the proposed relationship resembles empirical observations of Burton et al. (2013b).

Both the accumulation rate and extent of available resources (i.e., condition) influence maturation (Thorpe et al., 1990), as well as offspring performance (Burton et al., 2013a) and age at smoltification (i.e., smolt age) (Berrill, Porter, \& Bromage, 2006). We have no possibility to derive a reliable relationship between body condition and these traits. Accordingly, the implemented condition effect on age at sexual maturation in our model is arbitrary. Keeping in mind that implementation of a condition effect on traits such as smolt age and offspring survival can be crucial for simulation outcomes, we currently have no means to account for these and decided to ignore them at this stage.

Given the diversity of life histories between individuals (anadromous males vs mature male parr, size and age at maturity and smoltification, etc.) as a result of behavioural and morphological adaptations to maximize reproductive success, natural selection in the long run is expected to act in favour of some strategies over others, which is not considered by the model. In this process, demographic parameters would be shifted in order to counteract a potential population decline in response to perturbation. For example, we would expect a selection towards $2 \mathrm{SW}$ fish in the spawner stock owing to their relatively high fitness, particularly if reduced post-smolt condition would prolong the stay at sea of potential 1SW spawners. While such considerations are not implemented, the present condition-mediated model provides a potential framework for the implementation of relevant functional relationships between biotic and abiotic factors and salmon life-history traits, assuming a linkage can be made with condition factor. Thus, the mentioned limitations can be picked up if according relationships are compiled. 


\section{CONCLUSIONS}

Many mutually dependent factors at sea can contribute to the deterioration of marine survival in salmon stocks. These may include increasing temperatures in the marine habitat, pelagic fisheries and marine pollution, which can have an indirect effect on salmon via shifts in abundance and quality of salmon prey species, as well as directly inducing physiological stress (McLeay, 1975). All these factors can result in reduced growth, enervation and immunosuppression (Fast, Hosoya, Johnson, \& Afonso, 2008), increased predation rate (Mesa, 1994) and infestation with parasites such as sea lice and pathogens (Johnson \& Albright, 1992). In addition to being potentially lethal, predators, parasitic sea lice and pathogens can cause non-lethal effects compromising salmon body condition by inducing predator avoidance behaviour, nutrient deprivation or morbidity. The combined effect from these agents is likely synergistic, as infested individuals typically are favoured prey (Peacock, Krkošek, Bateman, \& Lewis, 2015), while fish hiding and evading predators are less able to compensate for the impact from sea lice infestation.

Non-lethal effects in Atlantic salmon are often disregarded by researchers for a number of likely reasons: insufficient data, effects can be subtle, time-consuming and costly to measure and quantify; they can be complex and have a delayed influence. Accordingly, due to lack of appropriate data, rationale management of Atlantic salmon stocks across the North Atlantic is often based on either fish weight or length to derive stock-recruitment relationships (SRRs) to implement conservation limits. Given the instability of the weight-length relationship as observed in Scottish stocks (Bacon et al., 2009), the neglect of condition effects (including those from sea lice) could introduce errors in SRRs. The present work has shown that even small non-lethal effects in the long run can be major drivers of salmon population dynamics, thus highlighting the importance of these effects for accurate assessment of the state of a population.

\section{ACKNOWLEDGEMENTS}

We thank Marine Scotland Science (MSS) for providing the studentship for this work. We are grateful to Alexander G Murray from MSS Aberdeen for providing data for model parameterization. We also want to thank Gordon Smith and lan Simpson from MSS Montrose, as well as the owner and staff of the net fishery at North Esk for enabling data collection. We thank Peerage of Science and two anonymous referees for constructive comments and critique points which considerably improved earlier drafts.

\section{ORCID}

R Susdorf iD http://orcid.org/0000-0002-0796-3817 N K G Salama iD http://orcid.org/0000-0002-5919-1847

\section{REFERENCES}

Anon (2015). The application of conservation limits for Atlantic Salmon in Scotland. Retrieved from http://www.gov.scot/Resource/0048/ 00486109.pdf.

Bacon, P. J., Palmer, S. C. F., MacLean, J. C., Smith, G. W., Whyte, B. D. M., Gurney, W. S. C., \& Youngson, A. F. (2009). Empirical analyses of the length, weight, and condition of adult Atlantic salmon on return to the Scottish coast between 1963 and 2006. ICES Journal of Marine Science, 66, 844-859.

Berrill, I. K., Porter, M. J. R., \& Bromage, N. R. (2006). The effects of daily ration on growth and smoltification in $0+$ and $1+$ Atlantic salmon (Salmo salar) parr. Aquaculture, 257, 470-481.

Bley, P. W., \& Moring, J. R. (1988). Freshwater and ocean survival of Atlantic Salmon and steelhead: A synopsis. Washington, DC: Fish and Wildlife Service, U.S. Dept. of the Interior.

Browne, J. (1988). The Use of Leslie Matrices to Assess the Salmon Population of the River Corrib. In D. Mills, \& D. Piggins (Eds.), Atlantic Salmon (pp. 275-300). Netherlands: Springer.

Burton, T., McKelvey, S., Stewart, D. C., Armstrong, J. D., \& Metcalfe, N. B. (2013a). Early maternal experience shapes offspring performance in the wild. Ecology, 94, 618-626.

Burton, T., McKelvey, S., Stewart, D. C., Armstrong, J. D., \& Metcalfe, N. B. (2013b). Offspring investment in wild Atlantic salmon (Salmo salar): Relationships with smolt age and spawning condition. Ecology of Freshwater Fish, 22, 317-321.

Castellani, M., Heino, M., Gilbey, J., Araki, H., Svåsand, T., \& Glover, K. A. (2015). IBSEM: An individual-based Atlantic Salmon population model, ed V. Laudet. PLoS ONE, 10, e0138444.

Caswell, H. (2001). Matrix population models: Construction, analysis, and interpretation. Sunderland, MA: Sinauer Associates.

Caswell, H., Naiman, R. J., \& Morin, R. (1984). Evaluating the consequences of reproduction in complex salmonid life cycles. Aquaculture, 43, 123-134.

Chaput, G., Allard, J., Caron, F., Dempson, J. B., Mullins, C. C., \& O'Connell, M. F. (1998). River-specific target spawning requirements for Atlantic salmon (Salmo salar) based on a generalized smolt production model. Canadian Journal of Fisheries and Aquatic Sciences, 55, 246261.

des Clers, S. (1993). Modelling the impact of disease-induced mortality on the population size of wild salmonids. Fisheries Research, 17, 237-248.

de Eyto, E., White, J., Boylan, P., Clarke, B., Cotter, D., Doherty, D., .. O'Higgins, K. (2015). The fecundity of wild Irish Atlantic salmon Salmo salar L. and its application for stock assessment purposes. Fisheries Research, 164, 159-169.

Fast, M. D., Hosoya, S., Johnson, S. C., \& Afonso, L. O. B. (2008). Cortisol response and immune-related effects of Atlantic salmon (Salmo salar Linnaeus) subjected to short- and long-term stress. Fish \& Shellfish Immunology, 24, 194-204.

Finstad, B., Bjørn, P. A., Grimnes, A., \& Hvidsten, N. A. (2000). Laboratory and field investigations of salmon lice [Lepeophtheirus salmonis (Krøyer)] infestation on Atlantic salmon (Salmo salar L.) post-smolts. Aquaculture Research, 31, 795-803.

Friedland, K. D., MacLean, J. C., Hansen, L. P., Peyronnet, A. J., Karlsson, L., Reddin, D. G., .. McCarthy, J. L. (2009). The recruitment of Atlantic salmon in Europe. ICES Journal of Marine Science, 66, 289-304.

Gardner Pinfold (2011). Economic value of wild Atlantic Salmon.

Gurney, W. S. C., Bacon, P. J., Malcolm, I. A., MacLean, J. C., \& Youngson, A. F. (2015). The demography of a phenotypically mixed Atlantic salmon (Salmo salar) population as discerned for an eastern Scottish river. Marine Scotland Science, 6, 76 pp.

Holling, C. S. (1996). Engineering resilience versus ecological resilience. Engineering within Ecological Constraints, National Academies Press, Washington, D.C. 31-44. 
Hutchings, J. A., \& Jones, M. E. (1998). Life history variation and growth rate thresholds for maturity in Atlantic salmon, Salmo salar. Canadian Journal of Fisheries and Aquatic Sciences, 55, 22-47.

ICES (2015). Report of the Working Group on North Atlantic Salmon (WGNAS), 17-26 March, Moncton, Canada. ICES CM 2015/ ACOM:09. $332 \mathrm{pp}$.

Jager, H. I., Rose, K. A., \& Vila-Gispert, A. (2008). Life history correlates and extinction risk of capital-breeding fishes. Hydrobiologia, 602, $15-25$.

Johnson, S., \& Albright, L. (1992). Effects of Cortisol implants on the susceptibility and the histopathology of the responses of naive Coho salmon Oncorhynchus kisutch to experimental infection with Lepeophtheirus salmonis (Copepoda: Caligidae). Diseases of Aquatic Organisms, 14, 195-205.

Jonsson, B., \& Jonsson, N. (2004). Factors affecting marine production of Atlantic salmon (Salmo salar). Canadian Journal of Fisheries and Aquatic Sciences, 61, 2369-2383.

Jonsson, N., Jonsson, B., \& Hansen, L. P. (1998). The relative role of density-dependent and density-independent survival in the life cycle of Atlantic salmon Salmo salar. Journal of Animal Ecology, 67, 751-762.

Legault, C. M. (2004). Salmon PVA: A population viability analysis model for Atlantic Salmon in the maine distinct population segment. Massachusetts: U.S. Department of Commerce, Northeast Fisheries Science Center, Woods Hole. https://www.nefsc.noaa.gov/publications/crd/ crd0402/crd0402.pdf

Legault, C. M. (2005). Population viability analysis of Atlantic Salmon in Maine, USA. Transactions of the American Fisheries Society, 134, 549562.

MacKenzie, K., Longshaw, M., Begg, G. S., \& McVicar, A. H. (1998). Sea lice (Copepoda: Caligidae) on wild sea trout (Salmo trutta L.) in Scotland. ICES Journal of Marine Science, 55, 151-162.

Marino, J. A., \& Werner, E. E. (2013). Synergistic effects of predators and trematode parasites on larval green frog (Rana clamitans) survival. Ecology, 94, 2697-2708.

McCormick, S. D., Lerner, D. T., Monette, M. Y., Nieves-Puigdoller, K., Kelly, J. T., \& Björnsson, B. T. (2009). Taking it with you when you go: How perturbations to the freshwater environment, including temperature, dams, and contaminants, affect marine survival of Salmon. American Fisheries Society Symposium, 69, 195-214.

McLeay, D. J. (1975). Sensitivity of blood cell counts in juvenile Coho Salmon (Oncorhynchus kisutch) to stressors including sublethal concentrations of pulpmill effluent and zinc. Journal of the Fisheries Research Board of Canada, 32, 2357-2364.

Mesa, M. G. (1994). Effects of multiple acute stressors on the predator avoidance ability and physiology of Juvenile Chinook Salmon. Transactions of the American Fisheries Society, 123, 786-793.

Murray, A. G., \& Simpson, I. (2006). Patterns in sea lice infestation on wild Atlantic salmon returning to the North Esk river in eastern Scotland 20012003. Fisheries Research Services Internal Report No 20/06.

Peacock, S. J., Krkošek, M., Bateman, A. W., \& Lewis, M. A. (2015). Parasitism and food web dynamics of juvenile Pacific salmon. Ecosphere, 6, art264.

Piou, C., \& Prévost, E. (2012). A demo-genetic individual-based model for Atlantic salmon populations: Model structure, parameterization and sensitivity. Ecological Modelling, 231, 37-52.

Reimers, E., Kjorrefjord, A. G., \& Stavostrand, S. M. (1993). Compensatory growth and reduced maturation in second sea winter farmed Atlantic salmon following starvation in February and March. Journal of Fish Biology, 43, 805-810.
Robertson, C. T. (2005). Conservation of endangered Atlantic Salmon in Maine. MSc Thesis.

Russell, I. C., Aprahamian, M. W., Barry, J., Davidson, I. C., Fiske, P., Ibbotson, A. T., ... Todd, C. D. (2012). The influence of the freshwater environment and the biological characteristics of Atlantic salmon smolts on their subsequent marine survival. ICES Journal of Marine Science, 69, 1563-1573.

Shephard, S., Maclntyre, C., \& Gargan, P. (2016). Aquaculture and environmental drivers of salmon lice infestation and body condition in sea trout. Aquaculture Environment Interactions, 8, 597-610.

Smith, A. D. M., Brown, C. J., Bulman, C. M., Fulton, E. A., Johnson, P., Kaplan, I. C., ... Tam, J. (2011). Impacts of fishing low-trophic level species on marine ecosystems. Science, 333, 1147-1150.

Stubben, C. J., \& Milligan, B. G. (2007). Estimating and analyzing demographic models Using the popbio Package in R. Journal of Statistical Software, 22, 1-23.

Thorpe, J. E., Talbot, C., Miles, M. S., \& Keay, D. S. (1990). Control of maturation in cultured Atlantic salmon, Salmo salar, in pumped seawater tanks, by restricting food intake. Aquaculture, 86, 315-326.

Todd, C. D., Friedland, K. D., MacLean, J. C., Whyte, B. D., Russell, I. C., Lonergan, M. E., \& Morrissey, M. B. (2012). Phenological and phenotypic changes in Atlantic salmon populations in response to a changing climate. ICES Journal of Marine Science, 69, 1686-1698.

Todd, C. D., Hughes, S. L., Marshall, C. T., MacLean, J. C., Lonergan, M. E., \& Biuw, E. M. (2008). Detrimental effects of recent ocean surface warming on growth condition of Atlantic salmon. Global Change Biology, 14, 958-970.

Todd, C. D., Whyte, B., MacLean, J. C., \& Walker, A. (2006). Ectoparasitic sea lice (Lepeophtheirus salmonis and Caligus elongatus) infestations of wild, adult, one sea-winter Atlantic salmon Salmo salar returning to Scotland. Marine Ecology Progress Series, 328, 183-193.

Tveiten, H., Bjørn, P. A., Johnsen, H. K., Finstad, B., \& McKinley, R. S. (2010). Effects of the sea louse Lepeophtheirus salmonis on temporal changes in cortisol, sex steroids, growth and reproductive investment in Arctic charr Salvelinus alpinus. Journal of Fish Biology, 76, 2318-2341.

Verspoor, E., Beardmore, J. A., Consuegra, S., Garcia de Leaniz, C., Hindar, K., Jordan, W. C., ... Cross, T. F. (2005). Population structure in the Atlantic salmon: insights from 40 years of research into genetic protein variation. Journal of Fish Biology, 67, 3-54.

Webb, J., Verspoor, E., Aubin-Horth, N., Romakkaniemi, A., \& Amiro, P. (2007). The Atlantic Salmon (pp. 17-56). Oxford, UK: Blackwell Publishing Ltd. https://doi.org/10.1002/9780470995846.ch2

\section{SUPPORTING INFORMATION}

Additional Supporting Information may be found online in the supporting information tab for this article.

How to cite this article: Susdorf R, Salama NKG, Lusseau D. Influence of body condition on the population dynamics of Atlantic salmon with consideration of the potential impact of sea lice. J Fish Dis. 2017;00:1-11. https://doi.org/10.1111/ jfd.12748 